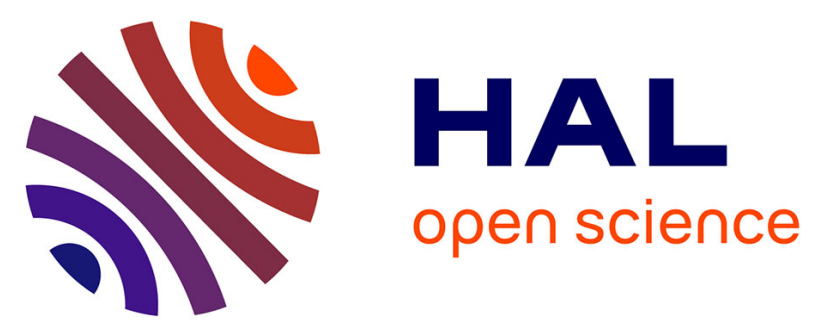

\title{
Uncertainties in assessing annual nitrate loads and concentration indicators. Part 1: Impact of sampling frequency and load estimation alogorithms
}

François Birgand, Claire Faucheux, Gérard Gruau, Bénédicte Augeard, Florentina Moatar, Paul Bordenave

\section{To cite this version:}

François Birgand, Claire Faucheux, Gérard Gruau, Bénédicte Augeard, Florentina Moatar, et al.. Uncertainties in assessing annual nitrate loads and concentration indicators. Part 1: Impact of sampling frequency and load estimation alogorithms. Transactions of the ASABE, 2010, 53 (2), pp.437-446. 10.13031/2013.29584 . insu-00578143

\section{HAL Id: insu-00578143}

https://hal-insu.archives-ouvertes.fr/insu-00578143

Submitted on 11 Oct 2011

HAL is a multi-disciplinary open access archive for the deposit and dissemination of scientific research documents, whether they are published or not. The documents may come from teaching and research institutions in France or abroad, or from public or private research centers.
L'archive ouverte pluridisciplinaire HAL, est destinée au dépôt et à la diffusion de documents scientifiques de niveau recherche, publiés ou non, émanant des établissements d'enseignement et de recherche français ou étrangers, des laboratoires publics ou privés. 


\title{
UnCertainties in Assessing Annual Nitrate LOADS AND CONCENTRATION INDICATORS: Part 1. Impact of SAMPLing Frequency AND LOAD Estimation AlgORithms
}

\author{
F. Birgand, C. Faucheux, G. Gruau, B. Augeard, F. Moatar, P. Bordenave
}

\begin{abstract}
The objectives of this study are to evaluate the uncertainty in annual nitrate loads and concentrations (such as annual average and median concentrations) as induced by infrequent sampling and by the algorithms used to compute fluxes. A total of 50 watershed-years of hourly to daily flow and concentration data gathered from nine watersheds (5 to $252 \mathrm{~km}^{2}$ ) in Brittany, France, were analyzed. Original (high frequency) nitrate concentration and flow data were numerically sampled to simulate common sampling frequencies. Annual fluxes and concentration indicators calculated from the simulated samples were compared to the reference values calculated from the high-frequency data. The uncertainties contributed by several algorithms used to calculate annual fluxes were also quantified. In all cases, uncertainty increased as sampling intervals increased. Results showed that all the tested algorithms that do not use continuous flow data to compute nitrate fluxes introduced considerable uncertainty. The flow-weighted average concentration ratio method was found to perform best across the 50 annual datasets. Analysis of the bias values suggests that the 90th and 95th percentiles and the maximum concentration values tend to be systematically underestimated in the long term, but the load estimates (using the chosen algorithm) and the average and median concentrations were relatively unbiased. Great variability in the precision of the load estimation algorithms was observed, both between watersheds of different sizes and between years for a particular watershed. This has prevented definitive uncertainty predictions for nitrate loads and concentrations in this preliminary work, but suggests that hydrologic factors, such as the watershed hydrological reactivity, could be a key factor in predicting uncertainty levels.
\end{abstract}

Keywords. Concentration indicators, Measurement uncertainty, Nitrate, Nutrient fluxes, Sampling strategies, Water quality, Watershed.

$\mathrm{E}$ xcessive nutrient export in watersheds has led to the development of large-scale monitoring programs and the implementation of Best Management Practices throughout the western countries. Documenting water quality improvement or degradation is not an easy endeavor. On a particular site, perceived improvement or degradation may result from year-to-year climate variability. Evaluating the quality of water in a watershed may consist of measuring the flux of a particular nutrient or pollutant at the outlet of the watershed. Flux values may be used for mass bal-

Submitted for review in October 2009 as manuscript number SW 8256 approved for publication by the Soil \& Water Division of ASABE in February 2010. Presented at the 2009 ASABE Annual Meeting as Paper No. 096601.

The authors are François Birgand, ASABE Member Engineer, Assistant Professor, Department of Biological and Agricultural Engineering, North Carolina State University, Raleigh, North Carolina; Claire Faucheux, Research Consultant, Geovariances, Avon, France; Gérard Gruau, Professor, CNRS-CAREN, Rennes, France; Bénédicte Augeard, Research Scientist, Cemagref, Antony, France; Florentina Moatar, Associate Professor, Laboratoire de Géologie des Environnements Aquatiques Continentaux, Université de Tours, France; and Paul Bordenave, Research Scientist, Cemagref, Bordeaux, France. Corresponding author: François Birgand, Department of Biological and Agricultural Engineering, Box 7625, North Carolina State University, Raleigh, NC 27695-7625; phone: 919-513-2499; fax: 919-515-7760; e-mail: francois_birgand@ncsu.edu. ance purposes or be compared from one year to the next. Water quality can also be assessed through concentration indicators that summarize in a few values "the" quality of water at a particular point in the watershed. Such indicators may include annual average, median, 90th and 95th percentile, and maximum concentrations (EU, 2000).

It is now well recognized that pollutant concentrations may vary widely with flow events and during the year in most watersheds and particularly in relatively small rural watersheds (e.g., Webb and Walling, 1985; Birgand, 2000). Concentrations may increase or decrease by several-fold (e.g., nitrate; this article) and sometimes by several orders of magnitude during the year (e.g., total suspended solids; Birgand et al., 2004; Meybeck et al., 2003), and when associated with flow events, in a matter of hours or even minutes.

Properly calculating fluxes or concentration indicators, as defined by the EU Water Framework Directive (EU, 2000), would imply having access to fine temporal records of both flow and concentrations. While such data are often available for flow rates (hourly or sub-hourly), the vast majority of the time concentration values are obtained from manual or automatic samples brought back to and analyzed in the laboratory. Because of the expenses of such acquisition methods, concentration data are most often available on an infrequent basis, and in the case of standardized regional and national monitoring programs in rivers, of the order of one to several dozen discrete samples per year. 
Since information on concentrations is not continuous, the potential for errors while calculating fluxes and concentration indicators exists. More generally, however, the overall uncertainty results from the combination of uncertainties induced during the monitoring and the calculation methods. They include uncertainties in measured flow rates and volume, uncertainties induced by infrequent sampling and the calculation algorithm, uncertainties induced by the actual location of the sampling station and of the intake in the water column, uncertainties induced by sample degradation between sampling and analysis, and uncertainties during laboratory analyses (reviewed in part in Harmel et al., 2006, and in Rode and Suhr, 2007). Quantifying the relative importance of each uncertainty component remains a difficult task (although attempts have been made by De Vries and Klavers, 1994, and Harmel et al., 2006) and requires prior evaluation of each component. The quantification of the magnitude of the errors on annual indicators induced by infrequent sampling is the first objective of this article.

The need for evaluating uncertainty resulting from infrequent concentration data is widely recognized in the literature (e.g., Littlewood, 1995; Kronvang and Bruhn, 1996; Webb et al., 1997, 2000; Littlewood et al., 1998; Horowitz, 2003; King and Harmel, 2003; Wang et al., 2003; Moatar and Meybeck, 2005, 2007; Birgand et al., 2006). Most such evaluations have been conducted for either rather large watersheds (several thousands of $\mathrm{km}^{2}$ ) and have focused on suspended solids (e.g., Crawford, 1991; Phillips et al., 1999; Webb et al., 2000; Horowitz, 2003) or rather small plot scale size watersheds (less than 5 km²; e.g., King and Harmel, 2003; Wang et al., 2003). Relatively fewer authors (e.g., Kronvang and Bruhn, 1996; Rekolainen et al., 1991; Birgand et al., 2006, 2009) have looked into the uncertainty of estimated pollutant loads at the outlet of intermediate size watersheds corresponding to surface water body size (5 to several hundreds of $\mathrm{km}^{2}$; e.g., Erba et al., 2009), which is relevant to the implementation of the EU Water Framework Directive (EU, 2000).

The range of errors in time proportional sampling schemes can vary widely depending on the type of pollutants, the size of the watersheds, the frequency of sampling, the period on which the indicators are computed, and the algorithm used to compute fluxes (e.g., Walling and Webb, 1981; Littlewood, 1992; Littlewood et al., 1998; Horowitz, 2003; Moatar and Meybeck, 2005). Reported uncertainties in annual load estimates from these algorithms and monthly sampling range from around $\pm 13 \%$ (e.g., nitrate on the Loire River in Orléans in France; Moatar and Meybeck, 2005) to $-80 \%$ to $+350 \%$ (e.g., TSS; De Vries and Klavers, 1994); however,
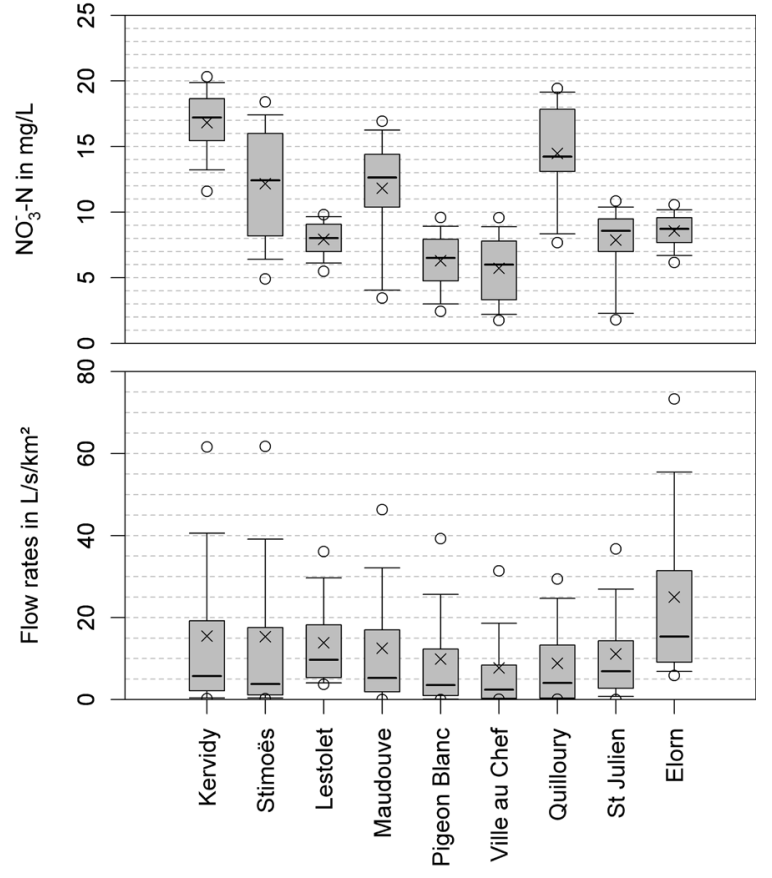

Figure 1. Boxplots of the variability over the periods of record (table 1) of concentrations and flow rates in the watersheds of study. Circles represent the 5th and 95th percentiles, whiskers represent the 10th and 90th percentiles, the lower and upper edges of the boxes represent the 25th and 75th percentiles, the thick horizontal line represents the median, and the $\times$ symbol represents the average.

these uncertainty values do not include uncertainties introduced by sample collection and analysis procedures. Comparison of the uncertainties introduced by various algorithms used to estimate constituent annual fluxes is the second objective of this article.

To our knowledge, there have been very few reports on uncertainties associated with concentration water quality indicators such as annual average $\left(C_{\mathrm{avg}}\right)$, median $\left(C_{50}\right), 90$ th and 95th percentile ( $C_{90}$ and $C_{95}$, respectively), and maximum $\left(C_{\max }\right)$. In this article, we examine uncertainties in calculating annual nitrate flux and concentration indicators from infrequent sampling at the outlet of intermediate size (5 to $252 \mathrm{~km}^{2}$ ) agricultural watersheds.

\section{MeThoD}

The method used a three-step process. The first step consisted of gathering "reference" datasets of flow and concentra-

Table 1. Physical characteristics, average nitrate loads, and time step and periods of monitoring for the watersheds of study.

\begin{tabular}{|c|c|c|c|c|c|c|}
\hline Station Name & $\begin{array}{c}\text { Watershed } \\
\text { Size } \\
\left(\mathrm{km}^{2}\right)\end{array}$ & $\begin{array}{c}\text { Average } \\
\text { Slope } \\
(\%)\end{array}$ & $\begin{array}{c}\text { Average Annual } \\
\mathrm{NO}_{3}^{--}-\mathrm{N} \text { Load } \\
\left(\mathrm{kg} \mathrm{ha}^{-1} \text { year }^{-1}\right)\end{array}$ & $\begin{array}{c}\text { Flow } \\
\text { Recording } \\
\text { Time Step }\end{array}$ & $\begin{array}{l}\text { Concentration } \\
\text { Recording } \\
\text { Time Step }\end{array}$ & $\begin{array}{l}\text { No. of Recorded } \\
\text { Years (and Period } \\
\text { of Record) }\end{array}$ \\
\hline Kervidy & 4.9 & 2.0 & 38.1 & Hourly & Hourly to daily & $6(2000-2006)$ \\
\hline Stimoës & 12.0 & 2.1 & 25.4 & $30 \mathrm{~min}$ & Hourly to daily & $2(2000-2002)$ \\
\hline Lestolet & 14.2 & 2.8 & 32.1 & Hourly & Hourly & $3(2001-2005)$ \\
\hline Maudouve & 24.2 & 3.7 & 46.9 & Hourly & Hourly & $8(1998-2006)$ \\
\hline Pigeon Blanc[a] & 24.2 & 1.9 & 15.5 & $15 \mathrm{~min}$ & Hourly to daily & $4(2000-2004)$ \\
\hline Ville au Chef ${ }^{[a]}$ & 35.1 & 1.7 & 16.2 & $15 \mathrm{~min}$ & Hourly to daily & $3(2001-2004)$ \\
\hline Quilloury & 38.5 & 3.0 & 47.7 & Hourly & Hourly & $1(2002-2003)$ \\
\hline St Julien & 138 & 3.7 & 29.4 & Hourly & Hourly & $10(1996-2005)$ \\
\hline Elorn & 252 & 3.7 & 61.9 & Daily & Daily & $13(1990-2003)$ \\
\hline
\end{tabular}

[a] Watersheds where artificial drainage is substantial. 
Table 2. Methods used and tested in this article to compute annual nitrate fluxes.

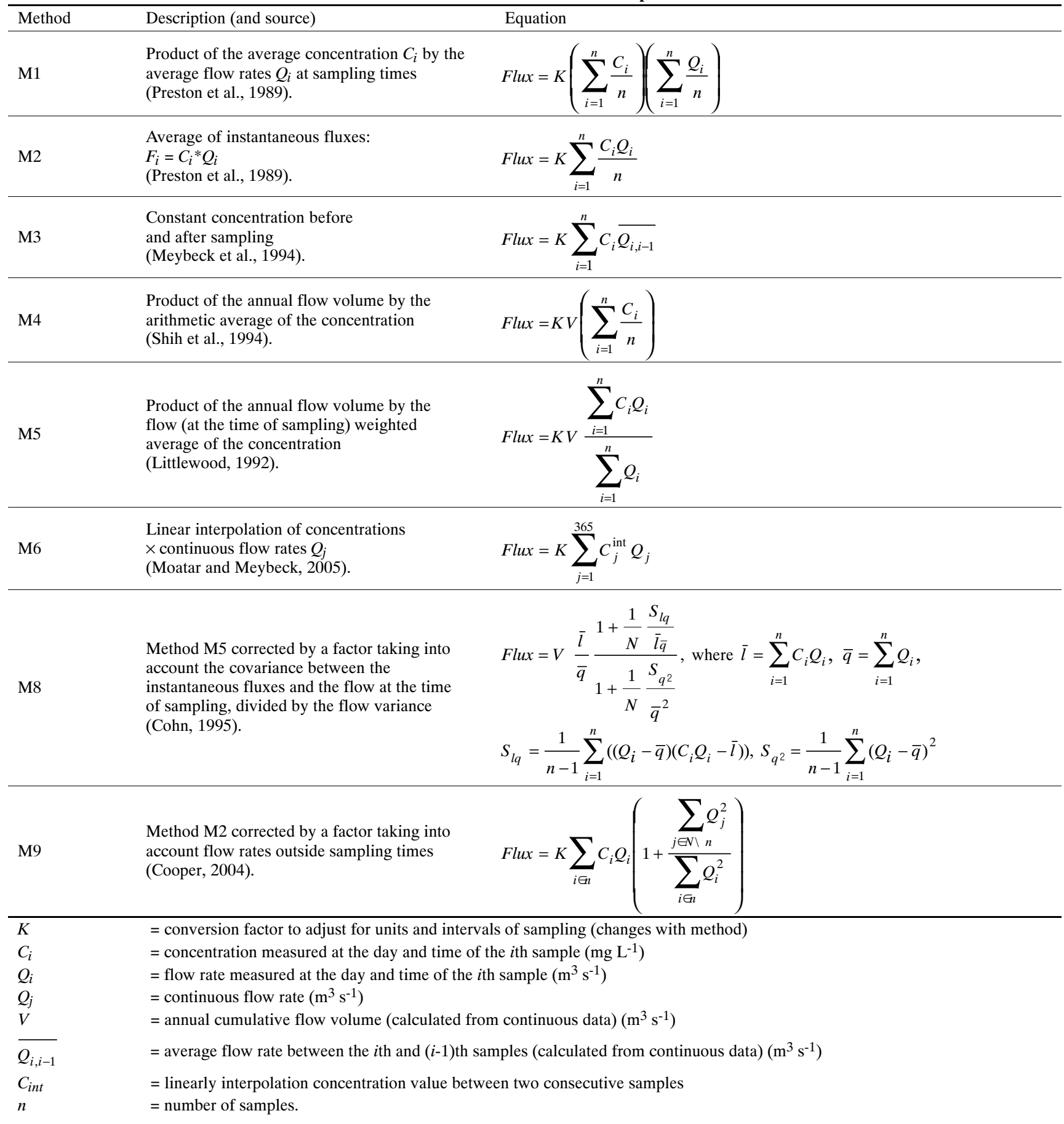

tion recorded at a high temporal resolution, usually hourly, from watersheds of variable sizes and characteristics in the intensive agricultural and animal rearing region of Brittany, France. Reference fluxes and concentration indicators were calculated from these datasets. In the second step, the reference datasets were numerically sampled to simulate discrete sampling at lower frequencies. For flux calculations, several algorithms were evaluated. In the third step, flux (load) estimates and water concentration indicators were calculated and compared to the reference values to estimate uncertainties (bias and precision) for a given sampling frequency and a given calculation algorithm for flux calculations.

We gathered the equivalent of 50 watershed-year datasets on nine watersheds ( 5 to $252 \mathrm{~km}^{2}$ ) throughout Brittany,
France. High temporal resolution data (hourly) for nitrate were often obtained from UV spectrometers installed in the field or from research watersheds where water was sampled and analyzed often enough (hourly to daily) such that a linear interpolation between consecutive samples likely represented actual concentrations (table 1).

Agriculture plays a major role in Brittany as a whole and encompasses more than $80 \%$ of the land in the study watersheds. Swine, cattle, and dairy rearing are major activities in the region (e.g., Aumaître, 1996). As a result, the nitrate loads (table 1) and concentrations (fig. 1) tend to be elevated. Flow rates generally ranged from 2 to $20 \mathrm{~L} \mathrm{~s}^{-1} \mathrm{~km}^{-2}$ for most watersheds, while the nitrate concentrations ranged from 5 to $20 \mathrm{mg} \mathrm{NO}_{3}^{--} \mathrm{N} \mathrm{L}^{-1}$ on the studied dataset (fig. 1). 
Data were arbitrarily grouped by "hydrologic" years that start and end at the end of the dry season, usually at the end of summer in Europe (1 Sept. to 31 Aug.). This reporting period was chosen for the following reasons: (1) hydrologic years include a full growing season, (2) flow and concentrations observed in winter are largely influenced by those that occurred in the previous fall, and (3) the dry periods tend to reset the hydrologic functioning at the end of each year.

It is important to realize that for a given sampling frequency, there are an infinite number of possible sampling dates and times. For example, using weekly sampling, concentration values obtained on Mondays at 10:00 a.m. have every chance to be different from concentration values obtained on Thursdays at 6:00 p.m. The calculated flux and concentration indicators therefore have a good chance to be different, although they were both calculated from weekly samples. The same reasoning can be applied to all sampling times. Thus, a theoretically infinite number of possible values exists for the estimators for any sampling frequency. Faucheux (2006) showed that 200 simulations were sufficient to represent the distribution of these values.

For the estimates, the uncertainty was represented by the bias and the precision of the distribution of the estimator. The precision was computed as the interval in which $90 \%$ of the estimated values were included (i.e., between the 5th and 95th percentiles, named herein precision limits $\mathrm{e}_{5}$ and e $_{95}$ ). The bias was represented by the average value ( $\left.e_{a v g}\right)$ of the distribution, although the median $\left(\mathrm{e}_{50}\right)$ value could also be used.

\section{LOAD ESTIMATION ALGORITHMS}

Many algorithms have been developed to calculate fluxes using infrequent concentration data, and both infrequent and continuous flow data (e.g., Phillips et al., 1999). Methods are commonly classified into averaging methods (M1 to M5, M8, and M9), interpolation methods (M6), and regression methods (none tested here) (e.g., Philips et al., 1999; Littlewood et al., 1998). In this article, we tested eight methods that seem to be most widely used. The descriptions are presented in table 2. The actual names of the methods correspond to the names commonly used in the literature.

Estimators of the concentration indicators were directly calculated from the numerically sampled values. Estimators of the flux using eight calculation methods plus five concentration indicators $\left(C_{\mathrm{avg}}, C_{50}, C_{90}, C_{95}\right.$, and $\left.C_{\max }\right)$ were calculated and compared to their reference values.

\section{RESUlTS}

\section{RELATIONSHIP BETWEEN FlOW AND Nitrate}

\section{Concentration in Brittany Watersheds}

In seven of the nine watersheds studied, nitrate chemographs always exhibited troughs when flow rates peaked. This is sometimes referred to as a dilution effect during hydrological events (e.g., Webb and Walling, 1985; fig. 2). This observation seems to be a characteristic of Brittany watersheds (average slope $3 \%$ on the studied watersheds; table 1) where bedrock is near the surface leaving only shallow aquifers and soils. Rain water tends to dilute the more concentrated water table and shallow aquifers during peak flow. In most studied watersheds in the world, however, nitrate concentrations exhibit dilution effects during winter but also exhibit concentration effects (concentration peak during

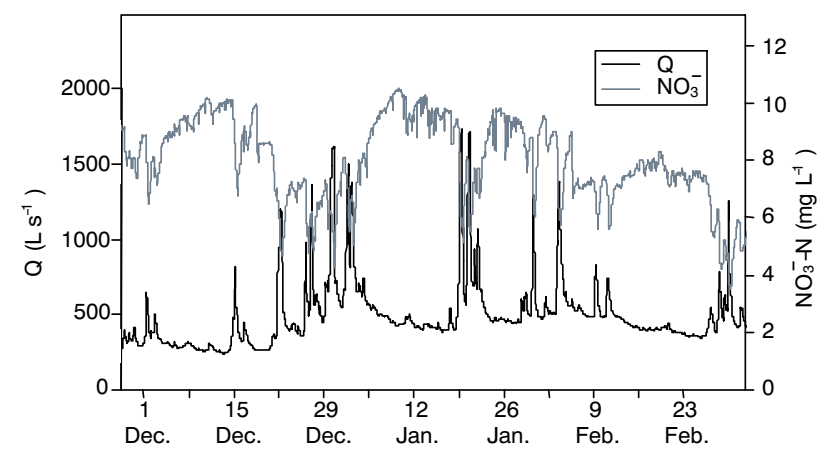

Figure 2. Typical systematic dilution effect of nitrate concentration during flow peaks in Brittany watersheds (Lestolet watershed in 2001-2002).

flow peaks) in part of the fall and spring (e.g., Webb and Walling, 1985; Birgand, 2000; Arlot, 1999; Billy et al., 2007; Tournebize et al., 2008). For the other two of the nine watersheds, where artificial drainage is widespread (average slope of $1.7 \%$ and $1.9 \%$; table 1 ), concentration effects were observed during several events in the spring and fall (data not shown). The unique and systematic dilution relationship has implications on the uncertainty associated with infrequent sampling (see subsequent discussion).

\section{Choosing the Best Algorithm for Computing Annual Nitrate FLUX}

The effect of both the sampling intervals and the type of algorithm used on the uncertainties of annual flux estimates are presented in figure 3 . Uncertainty descriptors $\left(\mathrm{e}_{5}, \mathrm{e}_{95}\right.$, $\mathrm{e}_{\mathrm{avg}}$, and $\mathrm{e}_{50}$ ) were calculated and plotted for sampling intervals ranging from $12 \mathrm{~h}$ to 60 days on a daily increment, while uncertainty distributions (vertical histograms) were plotted only for weekly increments for graphical clarity. Figure 3 clearly shows that uncertainty increased with increasing sampling intervals. It also shows that the algorithm used to compute fluxes has a dramatic effect on the bias and precision of the estimators.

Algorithms M1, M2, and M9 consistently induced both bias and precision that were much worse than for the others algorithms (fig. 3 and all watersheds-years; data not shown), prompting the suggestion not to use these algorithms. The poor performance of these algorithms is attributed to the fact that they do not use continuous records of flow rates. The availability of continuous flow measurement seems necessary to calculate nitrate fluxes with reasonable certainty. Precision generated using the remaining algorithms was generally smaller, often ranging between $-5\left(\mathrm{e}_{5}\right)$ and $+10 \%$ (e95) for monthly sampling.

Methods M3 and M4 induced little bias (<5\% in fig. 3), and M6 induced substantial bias ( $\mathrm{e}_{\text {avg }}$ lines drifting from the $y=0$ axis in fig. 3). Despite being biased, the precision for M3 was comparable to that of M5 and M8. Although biased, algorithm M4 induced the most precise results for all sampling intervals. Methods M5 and M8 were minimally biased, while their precision was in the same order of magnitude as M3 and M4 for the higher sampling intervals.

Similar plots as those in figure 3 were drawn for each of the 50 watershed-years. While M1, M2, M6, and M9 could be easily discarded as being clearly less desirable (e.g., fig. 3), the choice between the remaining methods (M3, M4, M5, and M8) was not as obvious. The analysis of the data revealed that there was much variability in the results 

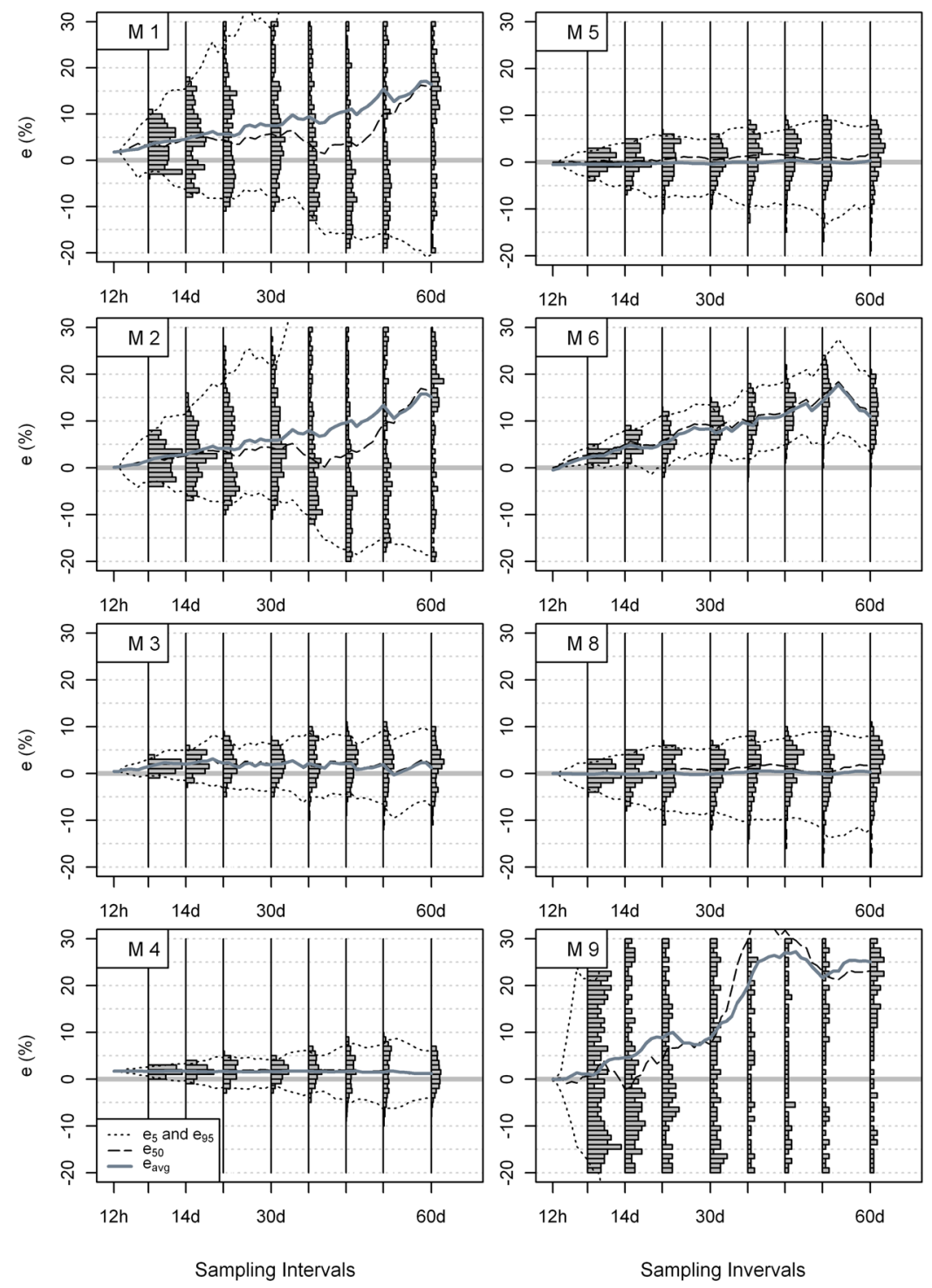

Figure 3. Comparison of the distribution of uncertainties on the estimation of the annual flux of the Elorn watershed in 1992-1993 as a function of sampling intervals and of the algorithm used (M1 to M9, see table 2). Vertical histograms represent distribution of uncertainty for sampling intervals corresponding to the vertical line abscises.

among watersheds and between years for the same watershed. The variability of the bias and precision over the period of record for each watershed was determined. For each sampling interval, the variability of the bias and precision values was expressed as the average and the standard deviation around the average. These values are plotted for sampling intervals ranging from $12 \mathrm{~h}$ to 60 days for three of the watersheds (fig. 4).

It then became very clear that both M3 and M4 induced variable and significant bias over the years of record (from $-20 \%$ to $+10 \%$ for M4 with monthly sampling at the Pigeon Blanc station; fig. 4), while much less variability and much smaller values $(+1 \%$ to $+5 \%$ for monthly sampling at the $\mathrm{Pi}-$ geon Blanc station; fig. 4) were observed for M5 and M8. Although better precision could be observed for M3 and M4 at times, these algorithms were discarded as being less desirable. The interannual variability analysis showed that the difference between M5 and M8 was very small. There seemed to be no noticeable difference for the bias, while precision seemed to be slightly better for M5 (fig. 4). As a result, the
M5 algorithm was chosen as the most desirable computation method to calculate annual nitrate loads in Brittany, France.

\section{UNCERTAINTY OF CONCENTRATION INDICATORS}

Results for concentration indicators also showed that uncertainties increased with increasing sampling intervals (fig. 5). Except for $C_{\max }$, the concentration indicator estimators were generally very slightly biased (generally between $\pm 5 \%$ for monthly sampling; figs. 5 and 6 ), although the results displayed in figure 5 show higher numbers for $C_{\mathrm{avg}}$ and $C_{50}$ for the Stimoës station in 2001-2002. Results for $C_{90}$ are not represented in figure 6 because they were very similar to those for $C_{95}$ (e.g., fig. 5). Both positive and negative biases were observed for $C_{\mathrm{avg}}$ and $C_{50}$. Only negative biases were observed for $C_{90}, C_{95}$, and $C_{\max }$ and increased in negativity in that order (figs. 5 and 6). Negative bias for annual maximum was obviously expected since this parameter can only be underestimated. Similarly, it was expected that estimating the 90th and 95th percentiles of a concentration distribution (values attained only $10 \%$ or $5 \%$ of the time, respectively) 

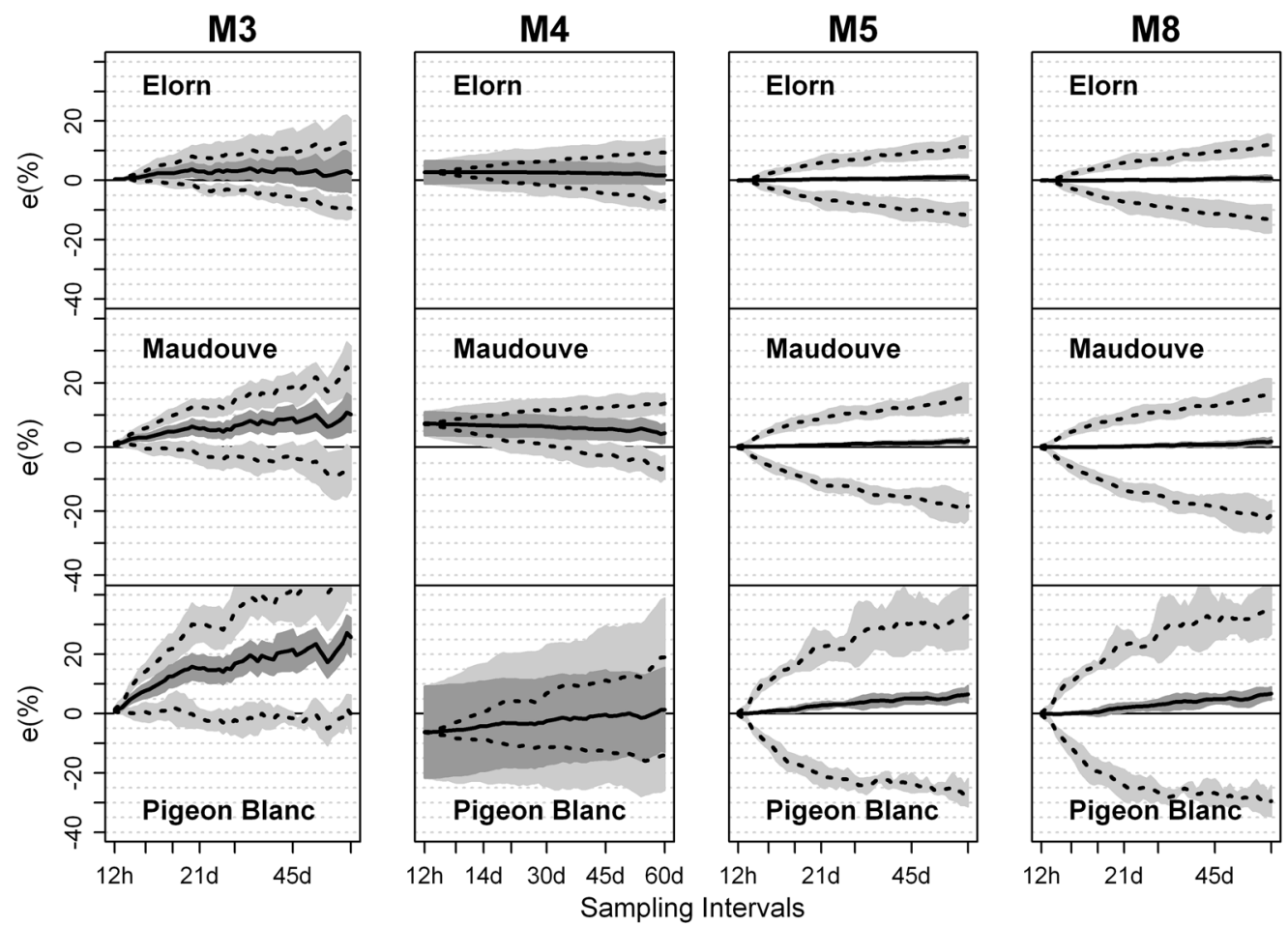

Figure 4. Interannual variability of bias and precision for load calculation algorithms M3, M4, M5, and M8 for three of the watersheds of study. The averages over the years of bias (solid line) and precision ( $e_{5}$ and $e_{95}$, dotted lines) are represented along with their variability (standard deviation around the average) as polygons in dark (bias) and light (precision) gray.
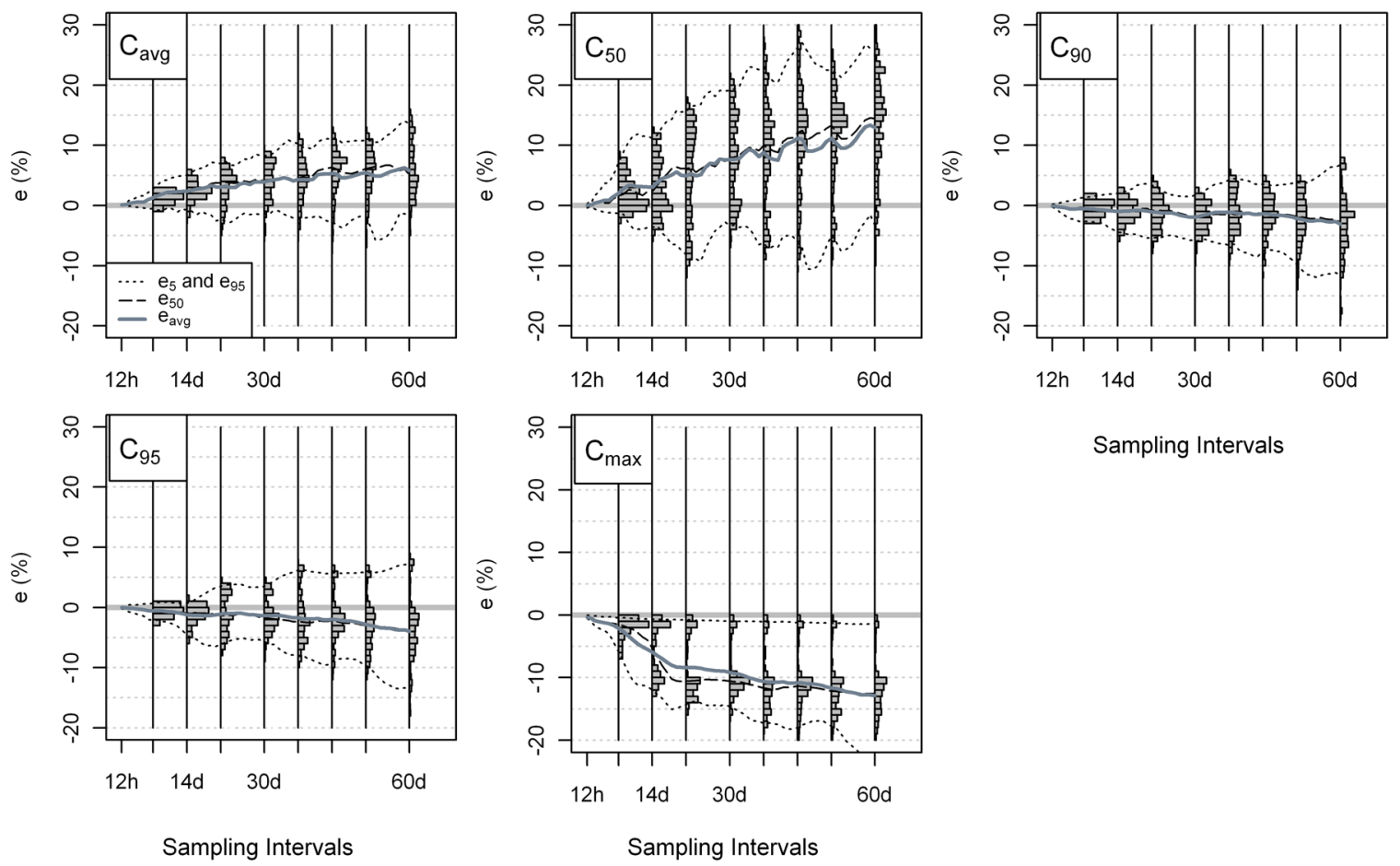

Sampling Intervals

Sampling Intervals

Figure 5. Comparison of the distribution of uncertainties on the estimation of the annual concentration indicators of the Stimoës station in 2001-2002 as a function of sampling intervals. Vertical histograms represent distribution of uncertainty for sampling intervals corresponding to the vertical line abscises.

using a time proportional sampling method could only lead to a negative bias.

The potential for overestimating and underestimating the indicators increased as sampling intervals increased for both $C_{\text {avg }}$ and $C_{50}$. The estimator of $C_{50}$ tended to be less precise than that of $C_{\text {avg }}$ (e.g., figs. 5 and 6). For non-drained wa- tersheds, overestimation of $C_{90}$ and $C_{95}$ only slightly increased with increasing sampling intervals, while the underestimation clearly increased as sampling intervals increased (e.g., figs. 5 and 6).

Results from the drained watersheds (Pigeon Blanc and Ville au chef; data not shown for the latter) for $C_{\max }$ were 

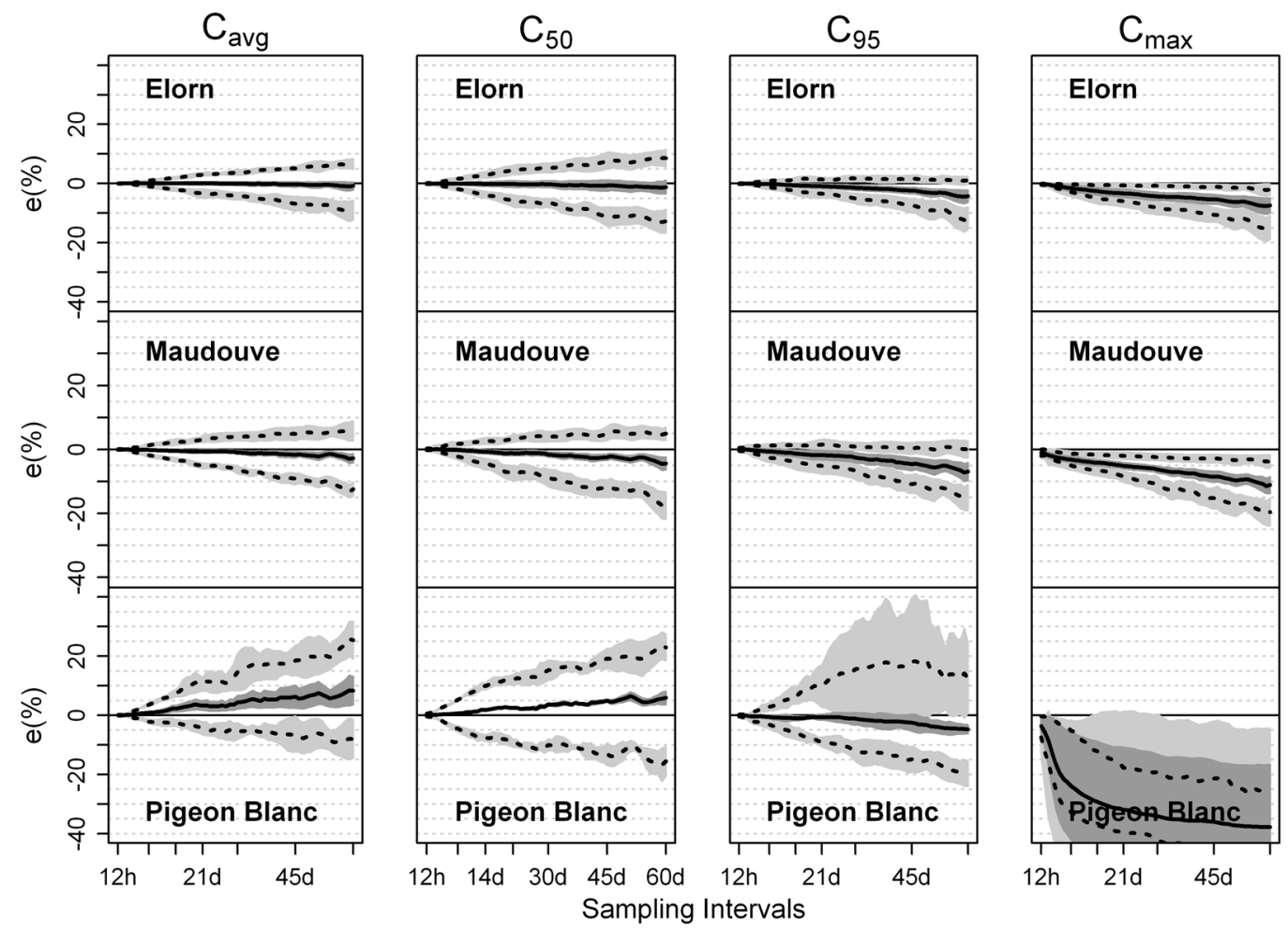

Figure 6. Interannual variability of bias and precision for the average, the median, the 95th percentile, and the maximum for three of the watersheds of study. The average over the years of bias (solid line) and precision ( $e_{5}$ and $e_{95}$, dotted lines) are represented along with their variability (standard deviation around the average) as polygons in dark (bias) and light (precision) gray.

drastically different compared to the non-drained watersheds. This is probably due to the fact that during some fall and spring events, flow peaks were accompanied by concentration peaks. Actual concentration maxima occurred during these few, short-lived events. The probability of sampling during these periods becomes very small as sampling intervals increase, hence the potential for very large underestimation for the drained watersheds (e.g., fig. 6). Conversely, in the other watersheds, concentration maxima would have occurred after event peaks during the relatively longer periods of the falling limb of the hydrographs where the concentration curves are "flatter" (fig. 2). The probability of sampling the maxima in these cases is not necessarily higher, but the difference between the actual maximum and the sampled value is relatively smaller, which reduces the potential for large errors.

For all watersheds, the 90th and 95th concentration percentiles corresponded to values found during the falling limbs of the hydrographs (data not shown). Because of the concentration peaks during some fall and spring flow peaks for the drained watersheds, the probability of sampling during these events was not negligible. In these cases, the estimated 90th and 95th percentiles could be largely overestimated compared to the actual values. This is the reason for the potential of gross overestimation as sampling interval increased in these watersheds (e.g., fig. 6).

\section{DisCUSSION}

In many regional and national standardized river water quality monitoring programs in western countries, water sampling is performed at set bimonthly, monthly, or bimestrial frequencies to derive annual indicators. These frequen- cies are, for instance, suggested for international conventions such as OSPAR (OSPAR, 2000), or now in the EU Water Framework Directive (EU, 2000), although more work is needed to document the uncertainties induced by load estimation procedures that utilize such infrequent samples.

It is important to keep in mind that the uncertainty values found in this article correspond to annual indicators. At no time can the uncertainty values be extrapolated to shorter periods, such as seasons or months, because the level of uncertainty is linked to the period over which the indicators are computed (Horowitz, 2003). In the case of loads, the errors on the annual indicators are a combination of both over- and underestimation of loads over the annual period. This approach was chosen because in many regional and national water quality monitoring networks, the annual values are used as a basis for analysis.

\section{Algorithm Choice to Calculate Annual nitrate FLUXES}

The least biased and still acceptably precise method was chosen as the best method to estimate annual nitrate fluxes. Both of these criteria depend on the sampling frequency and the algorithm chosen (fig. 3). Results show that the algorithms that do not use a continuous record of flow rates (M1, M2, and M9) perform very poorly, yielding biased and imprecise results (fig. 3). Availability of continuous flow measurement is thus necessary to calculate nitrate fluxes with reasonable uncertainty.

The M5 algorithm, which multiplies the annual flow volume by an estimator of the flow-weighted concentration, was chosen to be the most desirable of the tested methods. The M8 algorithm, which was initially developed to improve precision generated by the M5 algorithm for total suspended solids (Richards 
and Holloway, 1987), was not chosen, as this improvement could not be seen in our case for nitrate (figs. 3 and 4).

Choice of M5 is in accord with a significant number of other reports that gave the same advice (e.g., Walling and Webb, 1981; Webb and Walling, 1985; Littlewood, 1992; Littlewood et al., 1998; Moatar and Meybeck, 2005; Moatar et al., 2006; Littlewood and Marsh, 2005). Other authors, however, have found better results using other methods. The linear interpolation method (M6) was preferred to M5 in Denmark for total nitrogen and phosphorus in small rural watersheds (8.5 and $103 \mathrm{~km}^{2}$; Kronvang and Bruhn, 1996). Moatar and Meybeck (2005) also reported that for the estimation of annual nitrate and phosphate fluxes on the Loire River at Orléans, France, M5 and M6 were found to be equally desirable. Algorithms M4 and M6 were preferred for total phosphorus, while M4 was found to be the best suited method for particulate phosphorus. Johnes (2007) also proposed that the choice of method to be used could depend on the foreseen sampling frequency based on the evaluation of sampling strategies for estimating annual total phosphorus fluxes on 17 small English rural watersheds (average size: $109 \mathrm{~km}^{2}$ ).

\section{VARIABILITY OF THE UNCERTAINTY Bias Variability}

Except for $C_{\max }$, bias was generally found to increase or decrease linearly with increasing sampling intervals. Linear regressions conducted between bias and sampling intervals were found to be significant (average of $\mathrm{R}^{2}$ values greater than 0.93 for all years and concentration indicators when the absolute value of the regression coefficient was greater than 0.02). The same regression conducted for $C_{\max }$ did not yield as good results, with $\mathrm{R}^{2}=0.83$ (e.g., fig. 5). Bias on the load estimator also linearly increased with sampling intervals (average of $\left.\mathrm{R}^{2}=0.94\right)$. In light of these results, it is possible to extrapolate bias calculated on, e.g., bimestrial sampling to bias at any sampling interval by linear interpolation.

Our analysis shows that the M5 load estimator is generally only slightly biased towards overestimation (less than $3 \%$ for bimestrial sampling for most watersheds; data not shown), which suggests that the M5 algorithm is quite robust (e.g., fig. 4). The estimators of the annual median $\left(C_{50}\right)$ and average $\left(C_{\mathrm{avg}}\right)$ concentrations were also slightly biased (e.g., fig. 6). Biases could be either positive or negative, and for a particular watershed they together were usually in the same direction. The drained watersheds seem to consistently produce a positive bias, while there seemed to be no clear tendency for the other watersheds (e.g., fig. 6). The level of bias remained low, though, and generally within $\pm 5 \%$ for bimestrial sampling (data not shown). Overall, the interannual variability of the biases for each watershed was found to be quite small for the load (M5) and all concentration indicators, except for $C_{\max }$ in the drained watersheds (e.g., fig. 6).

These results suggest that the estimators of the load and average and median concentrations are generally quite robust and that, in the long term, the values calculated each year in Brittany watersheds have very little bias towards over- or underestimation. This is not true for the 90th and 95th percentiles and the maximum values, for which time proportional sampling induces in the long term a systematic underestimation of the actual values. A more systematic analysis is provided in the accompanying article (Birgand et al., 2010).

\section{Precision Variability}

The original goal of this work was to summarize in a few values the expected uncertainty of load and concentration indicators that would be applicable throughout Brittany. Our results show that there is tremendous variability among watersheds and among years for a particular watershed. Figure 7 illustrates the interannual variability of the precision (characterized by $\mathrm{e}_{5}$ and $\mathrm{e}_{95}$ values) on the annual flux and all concentration indicators for monthly sampling (e95 values for $C_{\max }$ not plotted for clarity) as a function of the watershed surface area. Our results suggest that the precision on the annual load could range from $\pm 5 \%$ to $\pm 35 \%$ for monthly sampling, with an entire spectrum of values in the middle (fig. 7). Although the variability did not extend as much for the concentration indicators, the precision values differed up to seven-fold between watersheds.
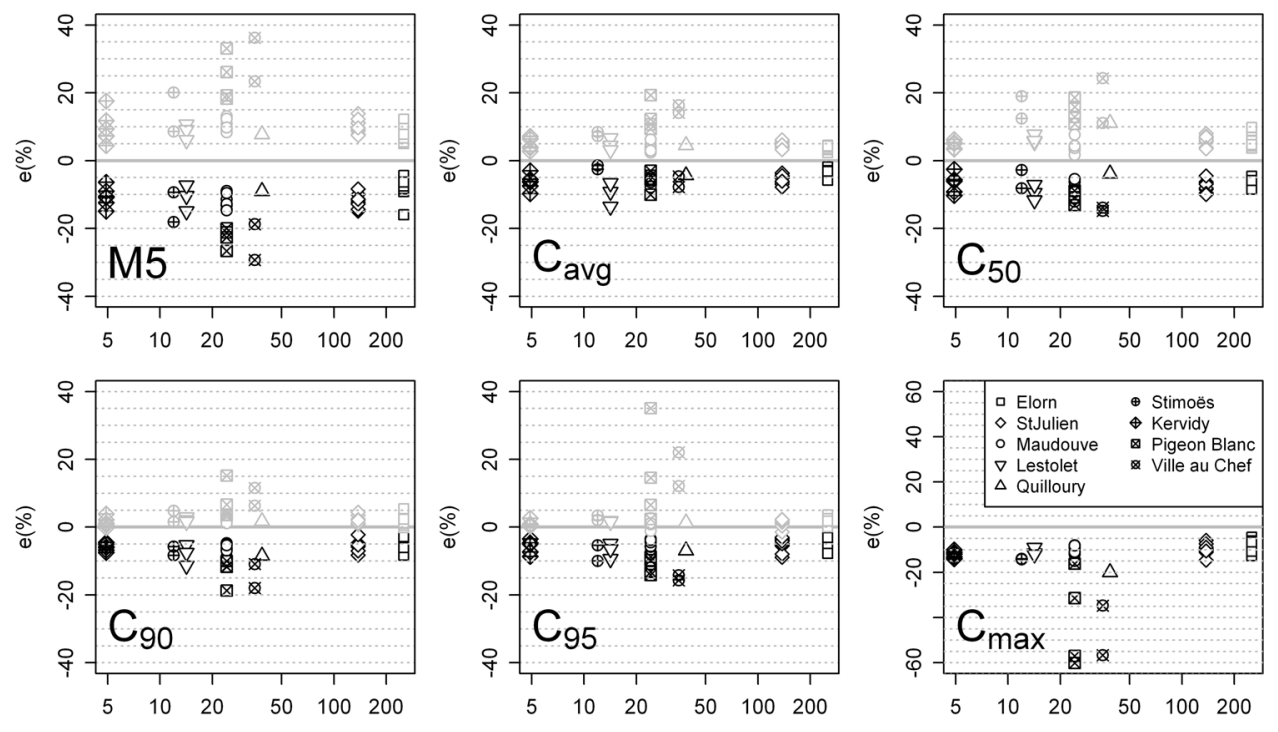

Watershed Surface Area $\left(\mathrm{km}^{2}\right)$

Figure 7. Interannual variability of the precision of annual fluxes (M5) and all concentration indicators ( $e_{5}$ and $e_{95}$ in black and gray, respectively) as a function of watershed size for monthly sampling. Each symbol corresponds to a particular year for a particular watershed. 
In addition, for all watersheds, precision could vary by two-fold depending on the years. For example, for the Pigeon Blanc watershed $\left(24.3 \mathrm{~km}^{2}\right)$, where four years of data were available, uncertainties on the annual flux could vary between $-36 \%$ and $-24 \%\left(\mathrm{e}_{5}\right)$ and between $+20 \%$ and $+39 \%$ (e95) depending on the years. This suggests that rainfall and climate variability in general play a major role in defining the level of uncertainty. The fact that the drained watersheds generate much less precise results than the other watersheds also suggests that the intrinsic hydrological regime within each watershed also plays an important role. Variability in load uncertainties has been reported in the past both at the plot scale (e.g., Wang et al., 2003) and at the large watershed scale (e.g., Moatar et al. 2006; Moatar and Meybeck, 2005, 2007; Johnes, 2007, Moatar et al. 2009). Moatar and Meybeck (2007) suggested that the hydrological reactivity of watersheds could be a key factor in predicting uncertainty levels. Deriving uncertainty values as a function of the hydrological regime is the subject of the accompanying article (Birgand et al., 2010).

The level of uncertainty introduced by infrequent sampling cannot be quantified with good precision as a result of this preliminary work. However, one can tell from figure 7 that uncertainty of the annual nitrate fluxes is roughly within $\pm 20 \%$ of the actual values for monthly sampling. This level of uncertainty is much better than the uncertainties commonly reported for parameters associated with total suspended solid (TSS) fluxes for watersheds of all sizes, where the range of errors may easily reach $\pm 50 \%$ or even higher for monthly sampling (e.g., Walling et al., 1992; Kronvang and Bruhn, 1996; Coynel et al., 2004; de Vries and Klavers, 1994; Moatar and Meybeck, 2007). To our knowledge, there are no other reports on the uncertainty levels found for concentration indicators. Figure 7 suggests that uncertainty of the annual average, median, and 90th and 95th percentile concentrations may roughly lie within $\pm 15 \%$, while the maximum concentration is generally not underestimated by more than $-20 \%$. A more detailed analysis of uncertainty values is provided in the accompanying article (Birgand et al., 2010).

\section{Conclusion}

The objectives of this work were to evaluate the uncertainty introduced by infrequent sampling and by the algorithms used to estimate annual nitrate flux and concentration indicators in regional and national water quality monitoring networks. We used a 50 watershed-year dataset (nine watersheds of 5 to $252 \mathrm{~km}^{2}$ in size) for which high temporal resolution data (hourly, daily at worst) were available for flow and nitrate concentrations. For each dataset, we calculated yearly reference fluxes and indicators. We then numerically simulated various sampling frequencies and applied common load estimation algorithms to compare to the reference loads. The choice of the algorithm used to compute the nitrate fluxes was found to largely determine the resulting accuracy and precision.

All methods that do not use a continuous record of flow performed very poorly and thus are not recommended. The flow-weighted average concentration ratio method was found to perform best across the 50 datasets. Results showed that, using the chosen algorithm, the load, the average, and the median concentration estimators were only slightly biased (within $\pm 3 \%$ for monthly sampling). The estimators of the 90th and 95th percentile concentration, as well as the maximum value, were found to be biased toward underestimating the actual values. These results suggest that the 90th and 95th percentiles and the maximum values will tend to be systematically underestimated in the long term, while this should not be the case for the load, the average, and the median concentrations.

Results show a great variability in the precision of the estimators, both between watersheds of different sizes and between years for a particular watershed. This has prevented an initial attempt to provide definite uncertainty values for monitoring nitrate indicators in this preliminary work. However, this suggests that the hydrological reactivity of watersheds could be a key factor in predicting uncertainty levels. Deriving uncertainty values as a function of the hydrological regime in watersheds is the subject of the accompanying article.

\section{ACKNOWLEDGEMENTS}

The authors thank Mrs. A. Bouédo for acquiring and providing to us great nitrate quality data without which little of this work could have been done. The authors also thank Eric Le Saos, Pascal Serrand, Patricia Saint-Cast, and Thierry Bioteau, Cemagref field, laboratory, and GIS technicians in Rennes, France, for their assistance in acquiring data on the partially drained watersheds. This research is a part of the Variflux project and was partially funded through the EC2CO, INSU/CNRS program.

\section{REFERENCES}

Arlot, M. P. 1999. Nitrate in water: Drainage as actor, or drainage as witness? Learning experience from both a hydrology and hydraulic approach. Unpublished PhD diss. Paris, France: University of Paris VI (in French).

Aumaître, A. 1996. Chapter 12. Pig production in Western Europe. In Pig Production, 10: 265-291. World Animal Science Subseries C: Production System Approach. M. R. Tavernier and A. C. Dunkin, eds. Amsterdam, The Netherlands: Elsevier Scientific.

Billy, C., C. Kao, F. Birgand, J. Tournebize, and M. Sebilo. 2007. Nitrate dynamics in a sub-surface artificially drained watershed. Geophys. Res. Abstr. 9: 11165.

Birgand, F. 2000. Quantification and modeling of in-stream processes in agricultural canals of the lower coastal plain. $\mathrm{PhD}$ diss. Raleigh, N.C.: North Carolina State University, Department of Biological and Agricultural Engineering.

Birgand, F., J. Lefrançois, C. Grimaldi, E. Novince, N. Gilliet, and C. Gascuel-Odoux. 2004. Flux measurement and sampling of total suspended solids in small agricultural streams. IngénieriesEAT. 40: 21-35 (in French).

Birgand, F., T. W. Appelboom, G. M. Chescheir, R. W. Skaggs, and J. W. Gilliam. 2006. Time proportional sampling strategies for estimating annual nutrient fluxes at the outlets of coastal plain watersheds. ASABE Paper No. 701P0406. St. Joseph, Mich.: ASABE.

Birgand, F., C. Faucheux, F. Moatar, and M. Meybeck. 2009. Uncertainties on nitrate water quality indicators associated with infrequent sampling in Brittany, France. ASABE Paper No. 096601. St. Joseph, Mich.: ASABE.

Birgand, F., C. Faucheux, G. Gruau, F. Moatar, and M. Meybeck. 2010. Uncertainties in assessing annual nitrate load and concentration indicators: Part 2. Deriving sampling frequency charts in Brittany, France. Trans. ASABE (in review). 
Cohn, T. A. 1995. Recent advances in statistical methods for the estimation of sediment and nutrient transport in rivers. Rev. Geophys. 33(S1): 1117-1123.

Cooper, D. M. 2004. Some effects of sampling design on water quality estimation in streams. Hydrol. Sci. 49(6): 1055-1080.

Coynel, A., J. Schafer, J. E. Hurtrez, J. Dumas, H. Etcheber, and G. Blanc. 2004. Sampling frequency and accuracy of SPM flux estimates in two contrasted drainage basins. Sci. Total Environ. 330: 233-247.

Crawford, C. G. 1991. Estimation of suspended-sediment rating curves and mean suspended-sediment loads. J. Hydrol. 129: 331-348.

de Vries, A., and H. C. Klavers. 1994. Riverine fluxes of pollutants: monitoring strategy first, calculation methods second. European Water Poll. Control 4(2): 12-17.

Erba, S., M. T. Furse, R. Balestrini, A. Christodoulides, T. Ofenböck, W. van de Bund, J.-G. Wasson, and A. Buffagni. 2009. The validation of common European class boundaries for river benthic macroinvertebrates to facilitate the intercalibration process of the Water Framework Directive. Hydrobiologia 633: $17-31$.

EU. 2000. Directive 2000/60/EC of the European Parliament and of the Council of 23 October 2000 establishing a framework for Community action in the field of water policy. Brussels, Belgium: European Parliament.

Faucheux, C. 2006. Evaluating water quality: Sampling strategies, determining indicators, and estimating annual fluxes of pollutants. MS thesis. Rennes, France: ENSA Rennes.

Harmel, R. D., R. J. Cooper, R. M. Slade, R. L. Haney, and J. G. Arnold, 2006. Cumulative uncertainty in measured streamflow and water quality data for small watersheds. Trans. ASABE 49(3): 689-701.

Horowitz, A. 2003. An evaluation of sediment curves for estimating suspended sediment concentrations for subsequent flux calculations. Hydrol. Proc. 17(17): 3387-3409.

Johnes, P. J. 2007. Uncertainties in annual riverine phosphorus load estimation: Impact of load estimation methodology, sampling frequency, baseflow index, and catchment population density. $J$. Hydrol. 332(1-2): 241-258.

King, K. W., and R. D. Harmel. 2003. Considerations in selecting a water quality sampling strategy. Trans. ASAE 46(1): 63-73.

Kronvang, B., and J. Bruhn. 1996. Choice of sampling strategy and estimation method for calculating nitrogen and phosphorus in small lowland streams. Hydrol. Proc. 10(11): 1483-1501.

Littlewood, I. G. 1992. Estimating constituent loads in rivers: A review. Report No. 117. Wallingford, U.K.: Institute of Hydrology.

Littlewood, I. G. 1995. Hydrological regimes, sampling strategies, and assessment of errors in mass load estimates for United Kingdom rivers. Environ. Intl. 21(2): 211-220.

Littlewood, I. G., and T. J. Marsh. 2005. Annual freshwater river mass loads from Great Britain, 1975-1994: Estimation algorithm, database, and monitoring network issues. J. Hydrol. 304: 221-237.

Littlewood, I. G., C. D. Watts, and J. M. Custance. 1998. Systematic application of United Kingdom river flow and quality databases for estimating annual river mass loads (1975-1994). Sci. Total Environ. 210/211: 21-40.

Meybeck, M., A. Pasco, and A. Ragu. 1994. Evaluation des flux polluants dans les rivières: Pourquoi, comment et à quel prix? Synthèse. Report produced under the direction of the French water agencies and the Ministry of the Environment (in French).

Meybeck, M., L. Laroche, H. H. Dürr, and J. P. M. Syvitski. 2003. Global variability of daily total suspended solids and their fluxes in rivers. Global and Planetary Change 39(1-2): 65-93.
Moatar, F., and M. Meybeck. 2005. Compared performances of different algorithms for estimating annual nutrient loads discharged by the eutrophic River Loire. Hydrol. Proc. 19(2): 429-444.

Moatar, F., and M. Meybeck. 2007. Riverine fluxes of pollutants: Towards predictions of uncertainties by flux duration indicators. Comptes Rendus Geosci. 339(6): 367-382.

Moatar, F., G. Person, M. Meybeck, A. Coynel, H. Etcheber, and P. Crouzet. 2006. The influence of contrasting suspended particulate matter transport regimes on the bias and precision of flux estimates. Sci. Total Environ. 370(2-3): 515-531.

Moatar, F., F. Birgand, M. Meybeck, C. Faucheux, and S. Raymond. 2009. Uncertainties on river water quality metrics assessment (nutrients, concentration quantiles, and fluxes) based on discrete surveys. Houille Blanche 3 (June): 68-76 (in French).

OSPAR. 2000. Guideline 7: Quantification and reporting of the monitored riverine load of nitrogen and phosphorus, including water flow normalisation procedures. Reference No. 2000-12. London, U.K.: OSPAR Secretariat.

Phillips, J. M., B. W. Webb, D. E. Walling, and G. J. L. Leeks. 1999. Estimating the suspended sediment loads of rivers in the LOIS study area using infrequent samples. Hydrol. Proc. 13(7): 1035-1050.

Preston, S. D., V. J. Bierman Jr., and S. E. Silliman. 1989. An evaluation of methods for the estimation of tributary mass loads. Water Resour. Res. 25(6): 1379-1389.

Rekolainen, S., M. Posch, J. Kämäri, and P. Ekholm. 1991. Evaluation of the accuracy and precision of annual phosphorus load estimates from two agricultural basins in Finland. J. Hydrol. 128: 237-255.

Richards, R. P., and J. Holloway. 1987. Monte Carlo studies of sampling strategies for estimating tributary loads. Water Resour. Res. 23(10): 1939-1948.

Rode, M., and U. Suhr. 2007. Uncertainties in selected river water quality data. Hydrol. Earth Syst. Sci. 11(2): 863-874.

Shih, G., W. Abtew, and J. Obeysekera. 1994. Accuracy of nutrient runoff load calculations using time-composite sampling. Trans. ASAE 37(2): 419-429.

Tournebize, J., M.-P. Arlot, C. Billy, F. Birgand, J.-P. Gillet, and A. Dutartre. 2008. Quantification and understanding of nitrate fluxes: From the field edge to the watershed scale. Ingénieries Numéro spécial 86: 5-25 (in French).

Walling, D. E., and B. W. Webb. 1981. The reliability of suspended sediment load data. In Erosion and Sediment Transport Measurement, 177-194. Publ. No. 133. Wallingford, U.K.: IAHS.

Walling, D. E., B. W. Webb, and J. C. Woodward. 1992. Some sampling considerations in the design of effective strategies for monitoring sediment-associated transport. In Erosion and Sediment Transport Monitoring Programmes in River Basins, 279-288. Publ. No. 210. Wallingford, U.K.: IAHS.

Wang, X., J. R. Frankenberger, and E. J. Kladivko. 2003. Estimating nitrate-N losses from subsurface drains using variable water sampling frequencies. Trans. ASAE 46(4): 1033-1040.

Webb, B. W., and D. E. Walling. 1985. Nitrate behaviour in streamflow from a grassland catchment in Devon, U.K. Water Res. 19(8): 1005-1016.

Webb, B. W., J. M. Phillips, D. E. Walling, I. G. Littlewood, C. D. Watts, and G. J. L. Leeks. 1997. Load estimation methodologies for British rivers and their relevance to the LOIS RACS(R) programme. Sci. Total. Environ. 194-195: 379-389.

Webb, B. W., J. M. Phillips, and D. E. Walling. 2000. A new approach to deriving "best-estimate" chemical fluxes for rivers draining the LOIS study area. Sci. Total Environ. 251/252: 45-54. 